\title{
Biophysical modelling of snapper Pagrus auratus larval dispersal from a temperate MPA
}

\author{
A. Le Port ${ }^{1,2, *}$, J. C. Montgomery ${ }^{1,2}$, A. E. Croucher ${ }^{3}$ \\ ${ }^{1}$ Institute of Marine Science, Leigh Marine laboratory, University of Auckland, PO Box 349, Warkworth 0941, New Zealand \\ ${ }^{2}$ School of Biological Sciences, University of Auckland, Private Bag 92019, Auckland, New Zealand \\ ${ }^{3}$ Department of Engineering Science, University of Auckland, Private Bag 92019, New Zealand
}

\begin{abstract}
A high-resolution 3D biophysical model was used to investigate the patterns of larval transport for an important commercial and recreational temperate fish, snapper Pagrus auratus, from a well-established marine reserve (Cape Rodney to Okakari Point marine reserve, CROP), and spawning ground. Our focus was to study the effects of local hydrodynamics, contrasting larval vertical behaviours and changing El Niño-Southern Oscillation (ENSO) cycles (via their effect on wind forcing) on the potential larval supply to adjacent non-protected areas. The model suggests the CROP marine reserve provides significant larval subsidies within a relatively small scale $(\leq 40 \mathrm{~km})$, the details of which depend on larval behaviour and ENSO patterns. Changing ENSO patterns mostly affected the dispersal direction of larvae, while larval behaviour was a strong driver only under La Niña conditions. Modelling suggests that under El Niño conditions, snapper larvae are more likely to settle successfully and hence make a strong contribution to surrounding fished stocks. Understanding the contribution of MPAs to fisheries management will require multiple approaches. Modelling will help identify the strength of contributing physical and biological factors, and in due course enable site- and time-specific examples of larval subsidy to be generalised.
\end{abstract}

KEY WORDS: Biophysical model $\cdot$ Snapper $\cdot$ Larval dispersal $\cdot$ MPA $\cdot$ ENSO $\cdot$ Sparid

\section{INTRODUCTION}

In coastal marine systems, marine protected areas (MPAs) are increasingly being suggested as a strategy to protect biodiversity and/or maintain sustainable fisheries (Sale et al. 2005). Stocks adjacent to MPAs may benefit from adult spillover (Egli \& Babcock 2004, Russ et al. 2004), as well as from enhanced recruitment through larval dispersal from protected spawning grounds. The latter comes from the premise that protection from fishing leads to increased population sizes (Willis et al. 2003), and to larger, more productive individuals (Palumbi 2004, Beldade et al. 2012), thus providing enhanced larval subsidies to adjacent fished populations. The management of MPAs and fisheries relies on knowing the extent and patterns of connectivity. We know little about the fate of the increased reproduction that typically occurs inside marine reserves. This question is critical, because it addresses both the service function of reserves (e.g. export of larvae to fished areas) and the design of reserves (e.g. conservation networks connected through larval exchange). However, quantifying larval subsidies remains challenging, so empirical evidence for larval export from MPAs remains sparse (Pelc et al. 2009, Christie et al. 2010, Harrison et al. 2012).

The majority of shallow-water marine species have a 2-phase life cycle in which relatively sedentary, demersal adults produce pelagic, dispersive larvae (Leis 2006). The amount of time that larvae remain in the pelagic realm prior to settlement (coined pelagic lar- 
val duration or PLD) clearly has an important effect on the distance larvae are dispersed. PLD is thus one of the fundamental components examined in the study of population connectivity. During this pelagic phase, eggs, and later on, larvae, are exposed to a number of hydrodynamic forces such as advection (winds, tides) and diffusion (turbulence), which evidence from modelling has shown to greatly influence dispersal directions and trajectories of larvae, especially in the early ontogenetic stages (Limouzy-Paris et al. 1997, Kaplan 2006). Thus, the importance of integrating PLD and accurate, location-specific oceanographic data in dispersal models has long been accepted. Recently, the importance of incorporating biological and behavioural data into larval connectivity studies has also been recognised, as speciesspecific differences in the swimming behaviour, directionality and sensory capabilities have been documented (Clark et al. 2005, Leis et al. 2006, Montgomery et al. 2006, Leis 2007, Radford et al. 2012). The swimming capabilities of fish larvae have also been shown to be more than capable of influencing their dispersal trajectories in response to changing prey and environmental conditions (Clark et al. 2005, Leis et al. 2006, 2007b, Murphy et al. 2011). The importance of larval behaviour in mediating dispersal trajectories is also supported by a suite of recent genetic larval connectivity studies, mostly on coral reef species, showing surprisingly high levels of selfrecruitment and/or small-scale (10s to $100 \mathrm{~s}$ of $\mathrm{km}$ ) larval retention and recruitment to their natal habitat (Jones et al. 2005, Carreras-Carbonell et al. 2007, Planes et al. 2009, Christie et al. 2010, Saenz-Agudelo et al. 2011, Harrison et al. 2012, D'Aloia et al. 2013). How such behavioural traits mediate dispersal driven by the advective-diffusive field the larvae encounter is a critical area of research. Evidence from a growing number of high-resolution biophysical modelling studies suggests that the role and importance of larval behaviour in determining larval trajectories varies among taxa; for example, the early onset of swimming behaviour can result in the prevalence of local or self-recruitment (Paris et al. 2005, Cowen et al. 2006, Kough et al. 2013, Lacroix et al. 2013). Many confirm the trend seen in genetics studies. However, the impact of vertical migration on larval transport can also be spatially inconsistent (Lacroix et al. 2013), and in some cases, negligible (Kough et al. 2013). The production of realistic larval dispersal models depends on filling the many gaps in species-specific biological knowledge of targeted species in order to understand how these respond to the varied and complex suite of physical, biotic and environmental factors that affect the transport of marine larvae among locations (Cowen \& Sponaugle 2009).

Many of the effects of changing climatic conditions on larvae remain unknown. However, understanding and quantifying larval dispersal under such changing conditions is also of utmost importance as temporal recruitment patterns are often characterized by large variations in cohorts, which cause strong fluctuations in stock size.

The El Niño-Southern Oscillation (ENSO) is the strongest climate signal of global impact that affects marine ecosystems, by changing patterns of upwelling with a frequency of 2 to $7 \mathrm{yr}$ (McPhaden et al. 2006). The climatic variability in El Niño/La Niña events plays a crucial role in marine ecosystems and in particular in the successful recruitment of fish populations (Alheit \& Niquen 2004, Aburto-Oropeza et al. 2010, Lo-Yat et al. 2011), which can have farreaching bottom-up impacts on marine top predators (Quillfeldt \& Masello 2013). Ocean warming or cooling may affect local and regional current patterns, both altering the supply of food and nutrients to reefs and modifying the dispersal patterns of larvae (Munday et al. 2009), with direct effects on the ability of larval fish to survive and settle.

ENSO events vary in duration and intensity, but recent climate models predict an increased frequency and intensity in the pattern of ENSO cycles with climate change (Timmermann et al. 1999, Yeh et al. 2009). In the case of coastal New Zealand, increases in the frequency and magnitude of ENSO events bring numerous correlated changes involving wind stress, sea surface temperature (SST), nutrients and wave forces, all of which have localized variations (Schiel 2011). Biophysical models can help explore the relationship between changing ENSO events as a measure of climate variability, and various larval behavioural modes to investigate the ability of fish larvae to successfully settle to adequate habitats.

Snapper Pagrus auratus (Sparidae) is an abundant coastal, demersal fish that is widely distributed in the temperate to sub-tropical western Pacific waters of the Southern and Northern Hemispheres (Paulin 1990). It is one of the most sought-after inshore teleost species in northern New Zealand waters and supports a very valuable fishery (Ruegg et al. 2013). However, heavy levels of exploitation by both commercial and recreational fisheries place snapper under continuous pressure, and at least 1 out of 4 stocks is currently considered depleted (SNA8, Ministry for Primary Industries 2013). Snapper are longlived (60 yr) and sexual maturity is reached between the ages 2 and 5+ yr (Francis \& Pankhurst 1988). 
While some adults are highly territorial, showing high levels of site fidelity to areas encompassing as little as a few 100 m wide (Egli \& Babcock 2004, Parsons et al. 2010), others demonstrate long-distance movements $(\leq 476 \mathrm{~km})$ (Gilbert \& McKenzie 1999). They are serial spawners that produce batches of eggs daily in the water column during an extended spring-summer season (November to February) (Francis 1994). In the Hauraki Gulf, snapper spawning aggregations generally occur in near-shore high productivity waters in 20 to $30 \mathrm{~m}$ depth (Zeldis \& Francis 1998) Although low levels of spawning occur around the whole Gulf (Zeldis \& Francis 1998, Zeldis et al. 2005), multiple spawning aggregations (hot spots) exist (Zeldis \& Francis 1998). Tagging studies suggest the Cape Rodney to Okakari Point (CROP) marine reserve in NE New Zealand is such an aggregation (Egli 2007). Snapper larvae have rapid egg development $(\sim 1 \mathrm{~d})$ and a relatively short larval duration (18 to 32 d) (Francis 1994). The latter 2 factors equate to a relatively short PLD.

In the context of a larger inter-disciplinary study of larval connectivity, we aimed to characterise the possibility for larval subsidies of snapper from a well-established MPA to surrounding exploited populations, using a high-resolution 3D hydrodynamic model coupled with a particle-tracking model. We hypothesize that snapper at the CROP marine reserve will make a significant contribution to the recruitment in waters adjacent to the reserve. This is based on the following research: (1) the snapper density in the reserve is 20 times higher than outside the reserve (Smith et al. 2014); (2) the proportion of large individuals is much greater inside the marine reserve, and it is known from other studies that larger individuals are not only more fecund, but more successful breeders (Beldade et al. 2012); (3) multiple tagging studies have shown that these fish show a surprisingly high level of year-round residency and site fidelity (Willis et al. 2001, Egli \& Babcock 2004, Parsons et al. 2010); (4) we have direct acoustic and archival tag data suggesting that reserve animals spawn locally (Egli 2007); and (5) recent evidence suggests that recruitment variability of $0+\mathrm{yr}$ fish is strongly correlated with variability in the abundance of $P$. auratus larvae (Hamer et al. 2010).

Several lines of evidence suggest that larval behaviour may influence dispersal, both through the relatively early development of vertical behaviour (Pankhurst et al. 1991) as well as the ability of many species (including snapper) in the later larval stages to swim directionally and competently (Clark et al. 2005, Leis et al. 2006, 2007a). The vertical behaviour of New Zealand snapper is unknown; however, some information is available for other snapper populations, and a closely related species. Here, we characterise the effect of 3 vertical behavioural modes on the predicted spatial scale of snapper larval dispersal from the CROP marine reserve. We also investigate how these patterns of dispersal could be influenced by typical climatic changes linked to the ENSO cycle.

\section{MATERIALS AND METHODS}

\section{Modelling aims}

Although snapper Pagrus auratus in New Zealand have been relatively intensively studied, there are almost no quantitative data available regarding their larval vertical behaviour. Other, closely related sparid species are known to exhibit a wide larval variety of vertical behaviours (see 'Behavioural input', below). Hence, our aim in this work is to simulate a range of possible vertical movement behaviours and evaluate how they interact with different climatic scenarios. The simulations provide the likelihood of larvae reaching suitable settlement habitats within the scope of their pelagic larval duration, and how this might depend on larval behavior and ENSO patterns.

\section{Hydrodynamic model}

Currents and tides in and around the CROP marine reserve in northeast New Zealand were simulated numerically with a hydrodynamic model created using the RMA-10 software (King 2008). RMA-10 is a finite element simulator that allows the use of mixed 2D/3D elements and simulates wetting and drying of intertidal areas. Fig. 1 shows the extent of the model grid, which covers the entire Hauraki Gulf and has an open sea boundary enclosing Great Barrier Island and extending northwards as far as Whangarei. This grid used in this study is based on the one used by Croucher et al. (2005), but refined around the CROP marine reserve. It contains a total of 12261 grid nodes and 4133 bi-quadratic finite elements, ranging in size from approximately $50 \mathrm{~m}$ to $5 \mathrm{~km}$ across. Grid elements within approximately $10 \mathrm{~km}$ of the CROP marine reserve are simulated in 3D, with 4 different layers (giving 9 grid nodes in the vertical). This allows stratified flows (for example from wind-induced surface currents) to be simulated. The top layer covers $10 \%$ of the local water depth, with subsequent layers covering 20,30 and $40 \%$. The remainder of the grid 


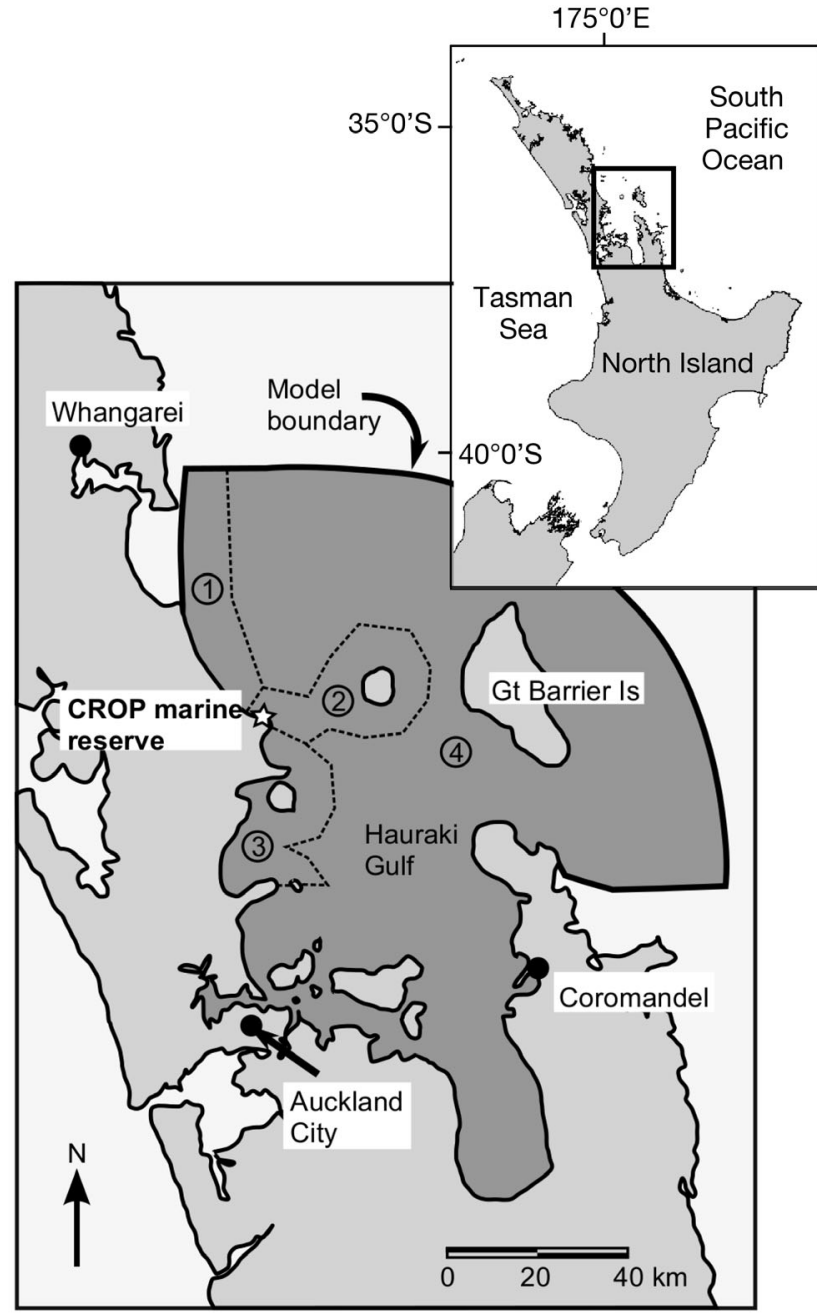

Fig. 1. Model grid boundary and layout of the 4 'zones' used to quantify the spatial distribution and abundance of larval snapper over time (28 d) (see Fig. 5). The most common habitat types found in each zone are (1) surf zone, (2) coastal reefs, (3) estuaries and harbours near the marine reserve spawning ground, and (4) 'offshore'. Each is surrounded by a $~ 10 \mathrm{~km}$ 'settlement' buffer area. See text for more detailed description of criteria. The Cape Rodney to Okakari Point (CROP) marine reserve, which includes Goat Island, is indicated by a star

is simulated using a depth-averaged 2D formulation to reduce computational cost. Water depths reach $150 \mathrm{~m}$ at the open sea boundary of the model, but are less than 50 m over most of the Hauraki Gulf, and less than $35 \mathrm{~m}$ within the CROP reserve.

Tidal boundary conditions are prescribed along the open sea boundary, generated using the IOS tidal package (Foreman 1977) and tidal harmonic constituents calculated from the harmonic tidal model of New Zealand developed by Walters et al. (2001). For simplicity, wind forcing was applied uniformly across the model, based on Leigh weather station wind data from the CliFlo National Climate Database (http://cliflo.niwa.co.nz).

The hydrodynamic model was verified using current data time series collected using a current meter deployed at a point near Goat Island within the CROP marine reserve over 2 periods in September and October 1972 (corresponding approximately to mean and spring tides respectively). Currents generated by the model were in acceptable agreement with the measured data (Croucher 2008). Our modelled currents confirmed field studies and modelling by Black et al. (2005), which showed a large headland eddy forming northwest of Cape Rodney as the tide turns from ebb to flood, developing into a structure that is some $5 \mathrm{~km}$ long and $2 \mathrm{~km}$ wide (Fig. 2), rotating anti-clockwise. Results from the present hydrodynamic model indicate that it has a significant complicating influence on the shape and formation of the eddy, dividing it, at some parts of the tidal cycle, into several sub-eddies. The model also shows a recirculating current pattern in the vertical plane within the eddy, with a zone of upwelling near its centre, which was also predicted by Black et al. (2005). A similar, though much smaller eddy also forms to the south of Cape Rodney as the tide turns from flood to ebb. Further details of the hydrodynamic model, its verification and results can be found in Croucher (2008).

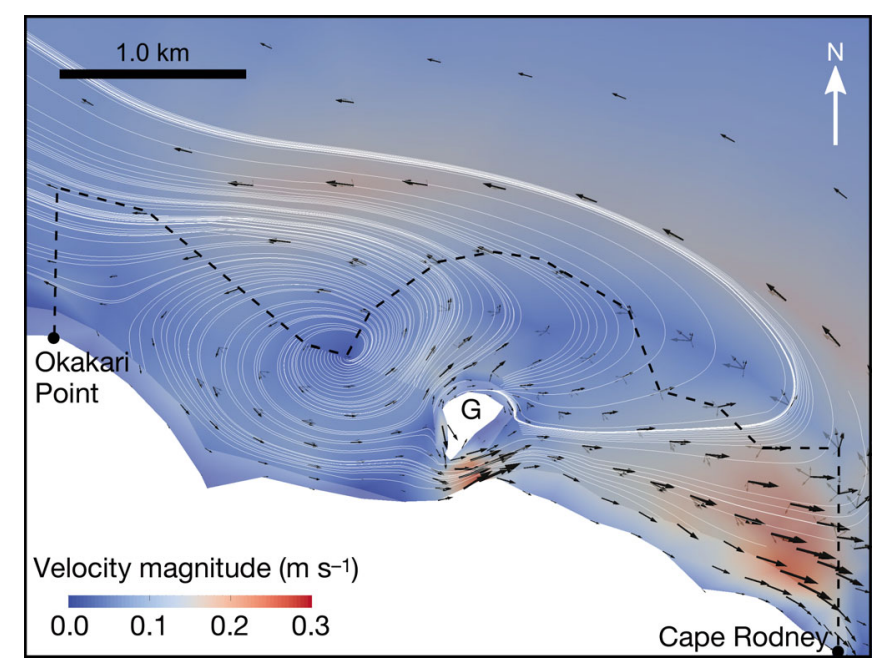

Fig. 2. Modelled mean tidal currents at the CROP marine reserve (see Fig. 1) showing the formation of a large headland eddy around low tide. Arrows indicate the velocities at the model grid nodes (results at multiple depths are shown within the 3D region of the grid). 'G' indicates the position of Goat Island within the marine reserve. Dashed line shows the boundary of the CROP marine reserve, which covers $5 \mathrm{~km}$ of coastline from Cape Rodney to Okakari Point and extends $800 \mathrm{~m}$ offshore 
Table 1. Behavioural and biological data used in the model in the present study, based on data from snapper (Pagrus auratus) populations in New Zealand (Pankhurst et al. 1991) and Australia (Murphy et al. 2011), and the sister species (P. major) in Japan (Kinoshita \& Tanaka 1990). Note: position in water column for P. major eggs assumed to be the same as for $P$. auratus.

Dph: days post-hatch

\begin{tabular}{|c|c|c|c|c|c|c|}
\hline \multirow{2}{*}{$\begin{array}{l}\text { Development } \\
\text { stage }\end{array}$} & \multirow[t]{2}{*}{ Dph } & \multirow{2}{*}{$\begin{array}{l}\text { Approx. } \\
\text { size } \\
(\mathrm{mm})\end{array}$} & \multicolumn{4}{|c|}{ - Position in water column } \\
\hline & & & $\begin{array}{l}P \\
\text { Day }\end{array}$ & Night & Day & Night \\
\hline Eggs & 0 & $0.8-1.0$ & Upper & Upper & Upper & Upper \\
\hline Yolk sack & $1-3$ & 2.0 & Upper-mid (4 m) & Distributed & Upper & Upper \\
\hline First feeding, pre-flexion & $4-5$ & $\leq 3.0$ & Upper-mid (4 m) & Distributed & Middle $(20 \mathrm{~m})$ & Distributed $(0-30 \mathrm{~m})$ \\
\hline Pre-flexion & $6-14$ & $3.0-5.0$ & Upper-mid (4 m) & Distributed & Near-bottom (20-30 m) & Distributed $(0-30 \mathrm{~m})$ \\
\hline Post-flexion & 15 & $>5.0$ & $?$ & ? & Near-bottom (30 m) & Distributed (0-30 m) \\
\hline Post-flexion & 25 & 7.5 & $?$ & ? & Near-bottom (30 m) & Distributed (0-30 m) \\
\hline Settlement & $28-32$ & $9.0-12.0$ & Mid-bottom & Mid-bottom & Distributed $(0-30 \mathrm{~m})$ & Distributed $(0-20 \mathrm{~m})$ \\
\hline
\end{tabular}

\section{Particle-tracking model}

The movement of snapper larvae was modelled using a Lagrangian particle-tracking simulator, in which each particle represents a number of larvae. The simulator is based on particle-tracking techniques used previously by Croucher \& O'Sullivan (1998) and Croucher et al. (2005).

The particle positions over time are determined by solving the differential equation of motion for each particle, based on the local water velocity. The differential equation is solved numerically using a secondorder Runge-Kutta method. The velocities are taken from the results of the hydrodynamic model, but with 2 modifications. Firstly, a small stochastic 'random walk' component of velocity is added, to represent the effects of turbulence. Secondly, in parts of the model grid represented in 2D rather than 3D, vertical variations in horizontal water velocity are simulated by applying a logarithmic velocity profile to the depth-averaged current results from the hydrodynamic model. Further details of the particle tracking model can be found in Croucher (2008). Finally, the particle-tracking model allows an additional velocity component to be added to each particle to represent the effects of buoyancy (primarily in the earlier stages of larval development) and larval behaviour. These effects are described below.

\section{Behavioural input}

The present study simulated the vertical behaviour of snapper larvae, as it is now well accepted that larvae are not passive drifters (Leis 2007). In order to document more realistic gradual behavioural transitions, we used 7 stages of larval development adapted from Pankhurst et al. (1991) to allow refinement of stage related parameterisation (Table 1). Newly hatched snapper larvae have a large yolk sac for the first few days after hatching, giving them positive buoyancy (Pankhurst et al. 1991). The size of this initial buoyancy velocity is not known, but in other pelagic fish species (Tallmon et al. 2012) float velocities of the order of $1 \mathrm{~mm} \mathrm{~s}^{-1}$ are common. For the present work, larvae were assumed to have constant positive buoyancy of $1 \mathrm{~mm} \mathrm{~s}^{-1}$ for the first $2 \mathrm{~d}$. At 1 to $3 \mathrm{~d}$ post-hatch (dph), larvae become more negatively buoyant as their yolk reserves reduce (Pankhurst et al. 1991). The larvae subsequently develop swimbladders, which start to inflate at around 4 to $5 \mathrm{dph}$ and can then be used to control buoyancy and maintain desired positions in the water column. Very little is known about the vertical distribution of postflexion stage snapper larvae. However, it is likely that as their swimming and sensory abilities increase when nearing settlement competency, so do their vertical migration abilities (Blower et al. 2012).

The importance of vertical behaviour in influencing the dispersal of snapper larvae from the CROP marine reserve was investigated by simulating 3 different behavioural modes. The first was 'no behaviour', and assumed neutral buoyancy and passive behaviour after the first $2 \mathrm{~d}$. This was used as a control to evaluate larval dispersal resulting from currents and wind only.

No in situ data are available on snapper vertical behaviour in New Zealand, thus the data for the other 2 behavioural modes were derived from $P$. auratus in Australia (Murphy et al. 2011) and the closely related red seabream P. major (Kinoshita \& Tanaka 1990). The behaviours in these studies differed markedly. Briefly, in the Australian study, snapper larvae exhibited nocturnal diffusion and aggregation at a specific depth stratum $(4 \mathrm{~m})$ during the day (Murphy et al. 2011). This pattern contrasts 
with the behaviour of other sparid larvae, including the sister species $P$. major, which displays nocturnal ascent and remains near the bottom during the day (Kinoshita \& Tanaka 1990). Modelling these 2 contrasting behaviours enables us to simulate the extremes of larval dispersal patterns expected to arise from varying behaviour. Interestingly, Murphy et al. (2011) did not find any ontogenetic differences in behaviour of pre-flexion stages, while Kinoshita \& Tanaka (1990) did. Vertical behaviour of $P$. auratus post-flexion stage is not known. For this study, we assumed the aggregation behaviour described above to continue into the post-flexion stage. A detailed description of diel behavioural data used in the model is provided in Table 1.

After the initial positive buoyancy stage, particles were given a depth-dependent vertical velocity to reproduce depth-aggregation behaviour. This velocity was negative above the specified preferred daytime feeding position (4 $\mathrm{m}$ from surface for Australian snapper, and $0.5 \mathrm{~m}$ from bottom for red seabream) and positive below it. The magnitude of vertical velocity was also specified, increasing with age up to $5 \mathrm{~cm} \mathrm{~s}^{-1}$ for $28 \mathrm{~d}$ old particles (comparable to, but less than known horizontal swimming speeds; Trnski 2002, Leis et al. 2006). However, the vertical velocity was reduced linearly to 0 within a specified distance from the preferred daytime feeding position, to cause particles to tend to settle at that position (rather than oscillating around it). In addition, vertical velocities were multiplied by a diurnal factor (1 during daylight hours and 0 at night) so that aggregation only occurred during the day, while at night particles were effectively neutrally buoyant. Within $1 \mathrm{~h}$ of sunrise and sunset (06:00 and 20:30 h, typical values for November at this latitude), this diurnal factor was varied linearly between its day and night values.

\section{Simulation periods and parameters}

Particle-release parameters and simulation length

At the start of each simulation, 5000 particles were released from one location around Goat Island (Figs. 1 \& 2), where tagging data from archival tags suggest snapper spawn (Egli 2007), and also where highest densities of large snapper are found. A sensitivity analysis showed that using 5000 particles gave sufficient accuracy, and using more resulted in little added benefit. Larval particles were released uniformly in the top $2 \mathrm{~m}$ of the water column simulating the snapper spawning runs to the surface.
The snapper spawning season extends from October to March, but peaks in November/December (Crossland 1977, Scott et al. 1993), with snapper larvae PLD ranging from 18 to $32 \mathrm{~d}$ in New Zealand waters (Francis 1994). In this study, we ran simulations for a length of $28 \mathrm{~d}$ (representing a typical larval duration) starting at peak spawning season from 1 to 28 November.

\section{Climatic input}

To evaluate the effect of changing ENSO conditions on larval dispersal, we selected 2 contrasting years with 'typical' La Niña and El Niño patterns. In New Zealand, El Niño years usually result in predominantly weak westerly winds and lower SST, while La Niña years tend to experience strong northeasterly winds and warmer SST (Mullan 1996). Simulating 2 contrasting climatic scenarios enables us to evaluate the likely associated variation in larval dispersal.

Wind data records during the peak spawning season period (1 to 28 November) were available for the years 2002 to 2012. Histograms of the wind speed and direction data were examined, in conjunction with the associated Southern Oscillation Index (SOI) values for the month, to determine typical La Niña and El Niño peak spawning periods. The year 2008 was chosen for the La Niña event (SOI = 2.2) and 2009 for El Niño (SOI = -1.0), both of which showed the expected wind patterns. The La Niña event included several storms, 2 of which (beginning around Day 8 and Day 23 of the simulation) had northeasterly winds reaching $10 \mathrm{~m} \mathrm{~s}^{-1}$.

\section{Dispersal zones}

The model grid was divided into a set of dispersal zones, to identify how many larval particles ended the modelled pelagic phase in an area deemed suitable for settlement. Suitable settlement habitats are often fragmented and cover only a small proportion of the area of potential dispersal (Cowen et al. 2006). However, settlement-competent snapper larvae can travel distances of up to $10 \mathrm{~km}$ without feeding (Clark et al. 2005) and so may still settle successfully if they are within that distance of suitable habitat at settlement time.

Our first dispersal zone (Zone 1) covered the area within $10 \mathrm{~km}$ of the coastline to the north of the CROP reserve (Fig. 1). This is a surf zone and unsuitable for snapper settlement. Zone 2 covered the area 
Table 2. Final distribution (\%) of particles in 4 predefined zones (see Fig. 1) under 3 different behaviours (no vertical behaviour, Pagrus auratus, P. major) and 2 typical climatic scenarios. Simulation run time $=28 \mathrm{~d}, \mathrm{~N}=5000$ particles. Zones 2 and 3 are deemed the most favourable for settlement

\begin{tabular}{|llcrcc|}
\hline $\begin{array}{l}\text { ENSO } \\
\text { event }\end{array}$ & Behaviour & Zone 1 & Zone 2 & Zone 3 & Zone 4 \\
\hline El Niño & None & 0 & 11 & 52 & 37 \\
$(2009)$ & P. auratus & 0 & 9 & 66 & 25 \\
& P. major & 0 & 4 & 67 & 29 \\
La Niña & None & 46 & 2 & 10 & 41 \\
$(2008)$ & P. auratus & 63 & 10 & 21 & 6 \\
& P. major & 4 & 14 & 8 & 74 \\
\hline
\end{tabular}

within $10 \mathrm{~km}$ of the coastal reefs near the CROP reserve (including offshore islands and the reserve itself), while Zone 3 covered the area within $10 \mathrm{~km}$ of the coastline (including estuaries and harbours) to the south. These 3 zones were of approximately equal area (ca. $500 \mathrm{~km}^{2}$ ). Zone 4 contained all offshore areas not covered by Zones 1 to 3 . Hence, only Zones 2 and 3 were deemed suitable for settlement.

\section{RESULTS}

\section{Predicted patterns of larval dispersal}

Our biophysical model predicts a substantial level of snapper larval subsidies from the CROP marine reserve to adjacent areas under the most favourable conditions (Figs. 3-5, Table 2). Both the addition of larval vertical behaviour and ENSO parameters to the model had an effect on the prediction of dispersal distance and spread from the CROP marine reserve, and thus likely settlement destinations.

Under typical El Niño conditions, larval vertical behaviour (or the absence thereof) does not greatly influence the distribution of larval snapper at the end of larval transport (Fig. 3) from the CROP marine reserve at time of settlement $(28 \mathrm{~d})$. As a result of the prevailing westerly winds, most dispersal would be expected in a SE direction out to a distance of about $40 \mathrm{~km}$ from the CROP reserve. Larvae with the Pagrus major vertical behaviour spend more time near the bottom, where they are less affected by wind-driven surface currents, and hence they are not generally dispersed as far. Also, under an El Niño cycle scenario, regardless of their vertical behaviour, the majority of larvae (63 to $75 \%$ ) are predicted to be within $10 \mathrm{~km}$ of adequate settlement areas (Zones 2

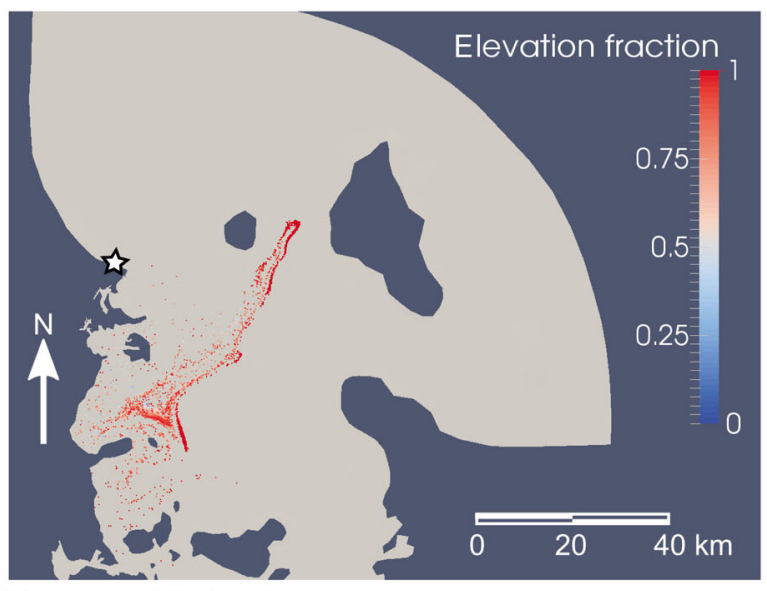

No vertical behaviour
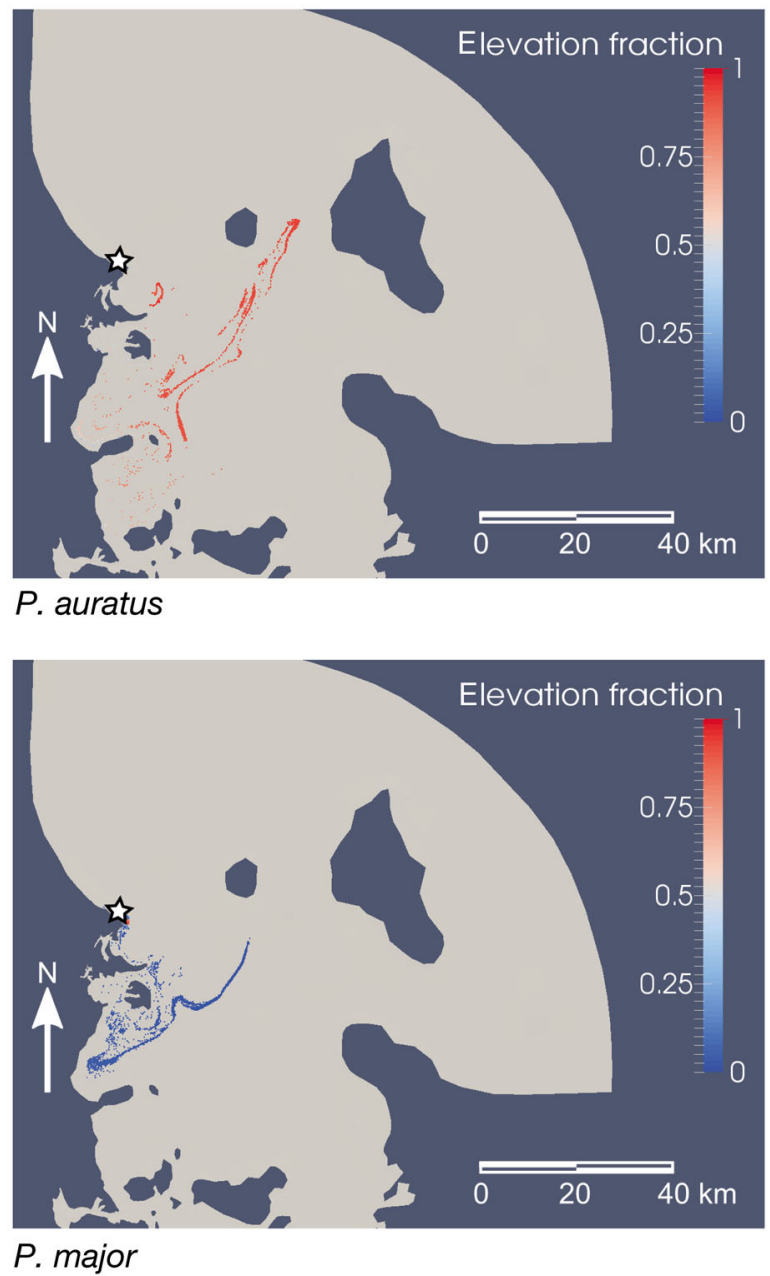

Fig. 3. Distribution of larval snapper at the end of larval transport from the spawning ground (CROP marine reserve, indicated by star) under El Niño climatic constraints (1 to 28 Nov 2009; 28 d). Three different behavioural modes are tested: passive (no vertical behaviour), Australian Pagrus auratus, and Japanese $P$. major. Note: particles are coloured relative their vertical distribution in the water column at Day 28 , with elevation fraction 0 at bottom and 1 at surface 
and 3), while none are likely to be found in Zone 1 (see Fig. 5, Table 2). Larval abundance in the 4 zones did not fluctuate much throughout their pelagic dispersal (see Fig. 5).

In contrast, in the La Niña climate cycle scenario, modelled larval behaviour was crucial in determining dispersal trajectories and distance (Fig. 4). At time of settlement $(28 \mathrm{~d})$, depending on the vertical behavioural mode applied, different settlement destinations are predicted: Zones 1 and 3 for ' $P$. auratus behaviour', or in Zones 2 and 4 for ' $P$. major behaviour' (Table 2). Interestingly, the predictions for $P$. auratus behaviour are not dissimilar to those for passive particles. As in the El Niño scenario, the modelled larvae have mostly dispersed less than $40 \mathrm{~km}$ from the CROP reserve. However under these conditions, the dispersal is mostly north of the original spawning location and along the coast (Zone 1), although some larvae have dispersed south (Figs. 4 \& 5). Under La Niña conditions, storm events with strong N-NE winds can blow particles back towards shore. This is particularly true for particles with $P$. auratus vertical behaviour, which tend to stay near the surface where they are affected more strongly by wind-driven surface currents. Some are blown into the large headland eddies near the CROP reserve, which, owing to their 3D rotating structure, can also redistribute the particles vertically. Under La Niña conditions, some particles are blown into sheltered estuaries and embayments; however, in general La Niña conditions may be less favourable for CROP marine reserve larvae to find 'good' settlement. Assuming that Zones 2 and 3 are the best settlement zones for snapper larvae, our model indicates that under La Niña conditions, only 12 to $31 \%$ of larvae would be in these zones at settlement time (Table 2). Larval abundance in the 4 zones changed dramatically around $8 \mathrm{dph}$, at which time a storm event with strong northeasterly winds occurred. For all 3 behaviours, the larvae had mostly been in Zone 2 up to that time, but were then moved mostly into Zone 1 (passive and $P$. auratus behaviours) or Zone 4 ( $P$. major behaviour) (Fig. 5).

Overall, the El Niño scenario predicts that snapper larvae are more likely to disperse within settling distance $(\leq 10 \mathrm{~km})$ of the more favourable settlement habitats (63 to $75 \%$ in Zones 2 and 3), regardless of snapper larvae vertical behaviour. In the La Niña scenario, only $\sim 12$ to $31 \%$ of larvae are predicted to disperse within range of suitable settlement habitats, with the majority of larvae ending up either in Zone 1 (63\%; 'P. auratus' behaviour) or Zone $4(74 \%$; 'P. major'behaviour) (Table 2).

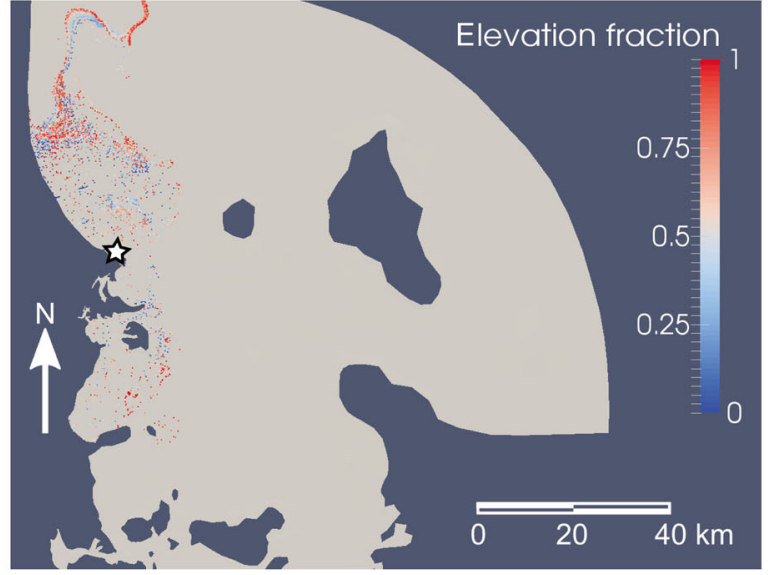

No vertical behaviour

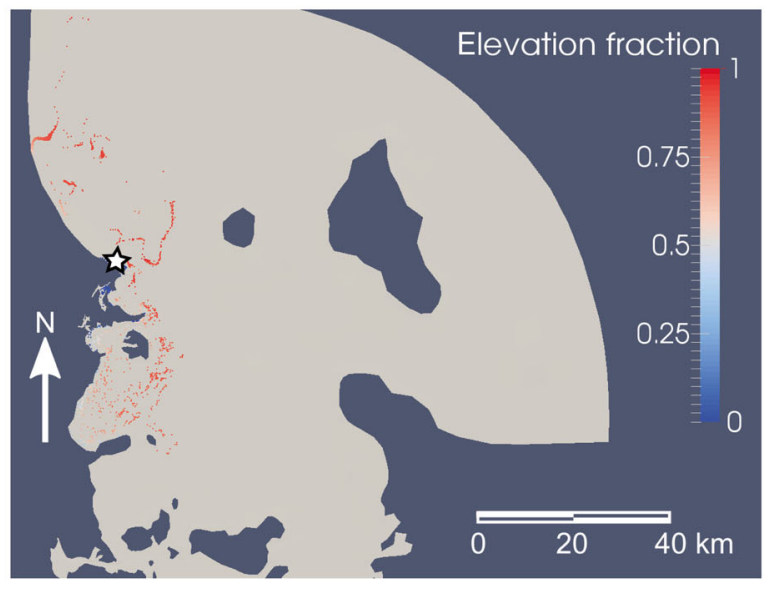

$P$. auratus

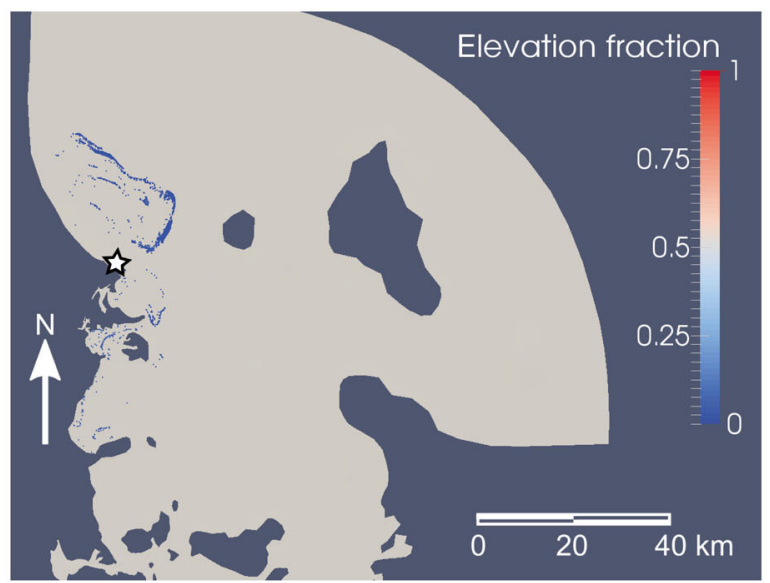

P. major

Fig. 4. Distribution of larval snapper at the end of larval transport from the spawning ground (CROP marine reserve, indicated by star) under La Niña climatic constraints (1 to 28 Nov 2008; 28 d). Three different behavioural modes are tested: passive (no vertical behaviour), Australian Pagrus auratus, and Japanese P. major. Note: particles are coloured relative their vertical distribution in the water column at Day 28, with elevation fraction 0 at bottom and 1 at surface 

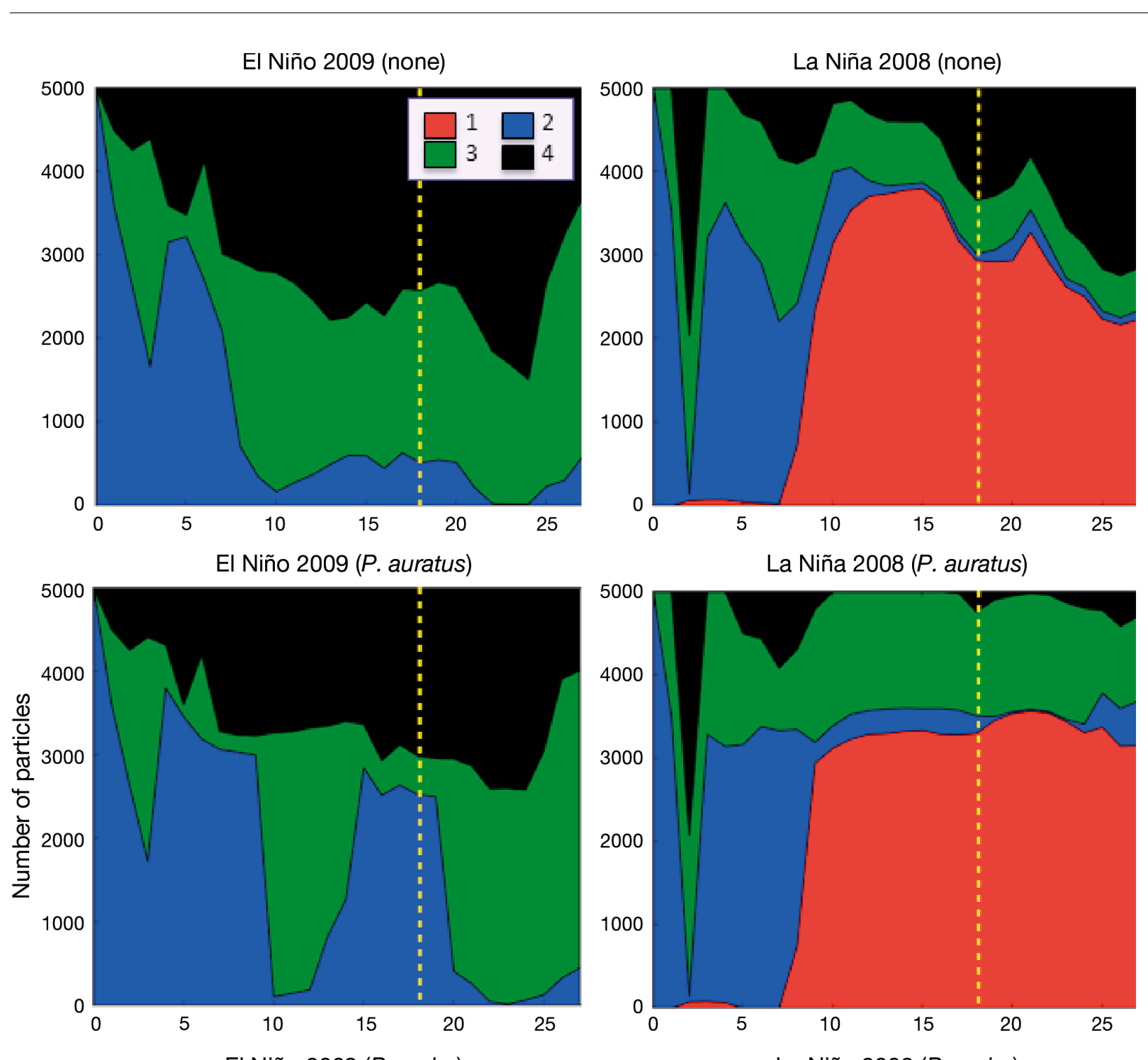

El Niño 2009 (P. major)
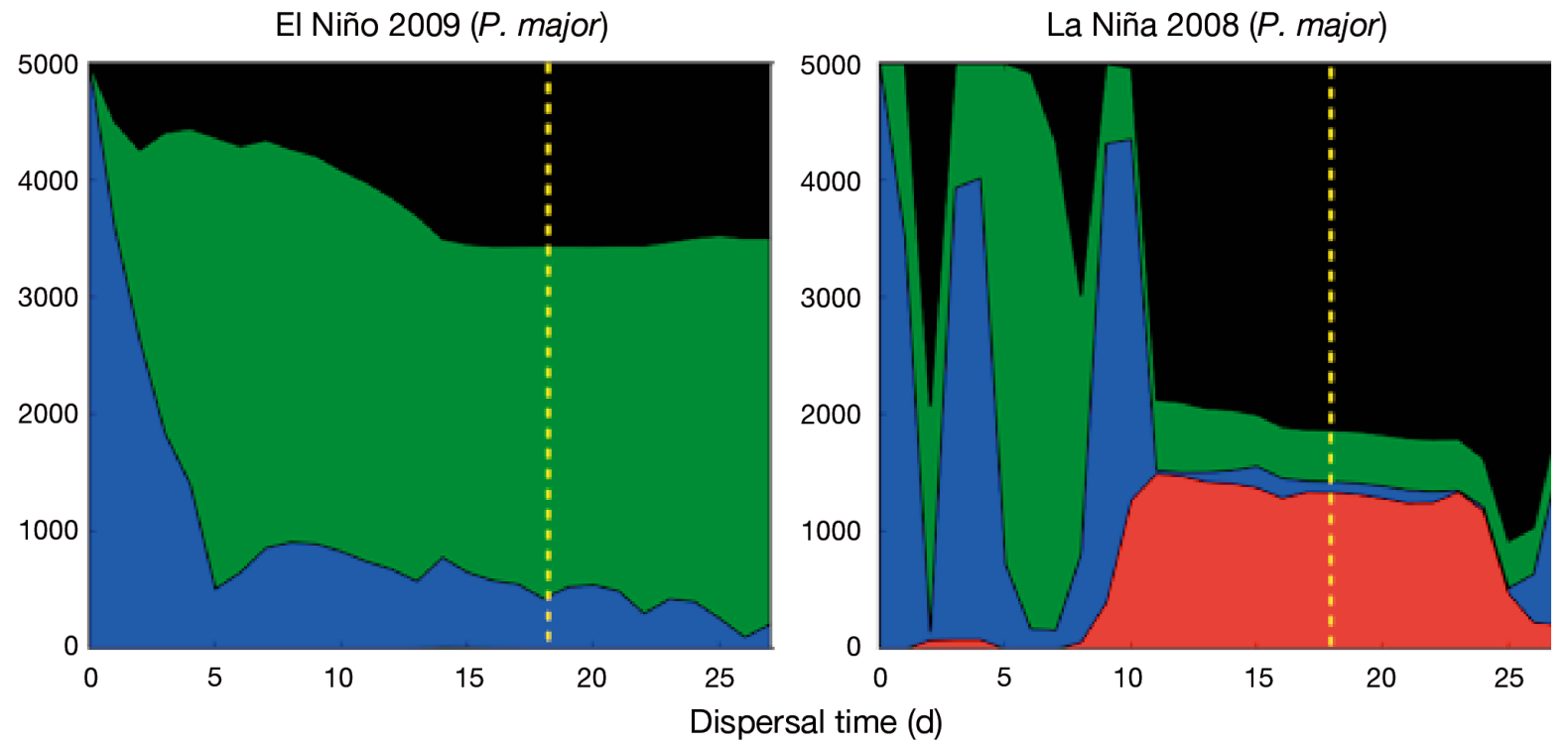

Fig. 5. Spatial distribution and abundance of larval snapper found in each of the 4 zones (see Fig. 1) during the pelagic larval duration (PLD; 28 d) under (a) El Niño, and (b) La Niña climatic conditions. Lower limit of PLD (18 d) is also indicated (vertical dashed line) 


\section{DISCUSSION}

We developed a high-resolution 3D biophysical model to investigate possible patterns of larval transport for snapper Pagrus auratus from the CROP marine reserve, northeastern New Zealand. Our main focus was to study the level of larval supply (larval subsidies) to adjacent non-protected areas in light of local hydrodynamics, likely larval vertical behaviour and changing ENSO conditions. Predictions from our biophysical model suggest that under the most favourable conditions there would be a substantial level of larval subsidies from the CROP marine reserve to adjacent areas $(\leq 40 \mathrm{~km})$, with up to $75 \%$ of all MPA larvae surviving PLD settling into adjacent fished populations.

\section{Model constraints}

In this study, only ontogenetic vertical behaviour was incorporated into our model. Active horizontal movement was not directly included, but settlement zones were extended $10 \mathrm{~km}$ offshore to accommodate likely onshore movement prior to settlement. Other species-specific biological attributes (e.g. reproductive output through the spawning season: temperature effects on larval mortality, growth, and PLD; orientation and sensory abilities) are known to increase the realism of biophysical models and should be targeted in further research on snapper larval dispersal.

With respect to PLD, the model was run for $28 \mathrm{~d}$, corresponding to the upper PLD range reported for this species (18 to 32 d) (Francis 1994). This range in PLD is thought to be influenced by water temperature and availability of suitable settlement habitat (Francis 1994, Murphy et al. 2013). There were few substantive differences in the spatial distribution and abundance of modelled larvae between 18 and $28 \mathrm{~d}$ (Fig. 5). During the El Niño scenario, there was a movement from Zone 2 to Zone 3 for the $P$. auratus behaviour between 18 and $28 \mathrm{dph}$, but both these zones are favourable for settlement, so the overall effect on predicted favourable settlement is small. Similarly, during the La Niña scenario, there was a movement from Zone 1 to Zone 4 for no vertical behaviour and P. major behaviour, but both these zones are unfavourable for settlement.

The 4 dispersal zones have been classified as more favourable for successful settlement of snapper larvae (Zones 2 and 3 ) or less favourable ( 1 and 4 ) based on the type of habitats they contain (e.g. coastal reefs, estuaries and harbours vs. sandy bottom or $>10 \mathrm{~km}$ from shallow biogenic structures). Complex biogenic structures have been shown to harbour the highest densities of settlement-stage snapper (Usmar 2009, Sim-Smith et al. 2013). This is likely because they provide greater abundance of food, refuge from predators and shelter from water currents than surrounding areas. For the purposes of this study, we assumed that Zones 1 and 4 were less suitable for settlement-ready snapper larvae due to their apparent lack of these complex structures. Zone 1 includes several river mouths (Pakiri, Mangawhai), which may prove to be productive enough to support snapper recruits. Further research is needed to ascertain this, as including this zone with the other suitable settlement areas (Zones 2 and 3 ) would increase the predicted larval contributions from the CROP marine reserve.

\section{Variation in larval behaviour}

Vertical behaviour was important in predicting settlement areas in snapper larvae. However, our study also highlights the importance of incorporating species-specific vertical behavioural data into biophysical models, as shown by the different model predictions resulting from the $P$. auratus and $P$. major behavioural modes in La Niña conditions. Thus, a one-size-fits-all approach to incorporation of larval behaviour into models is likely to be misleading, as behaviour differs greatly among species (Leis 2006, 2007 ) and possibly also within species. No in situ vertical behaviour data is available for $P$. auratus in New Zealand. However, data from plankton tows in the Hauraki Gulf (our study region) suggest that New Zealand snapper larvae may exhibit a similar diurnal vertical migration to Port Phillip Bay snapper (Murphy et al. 2011), maintaining a mid-water position during the day, but that instead of night-time diffusion, New Zealand larvae are generally more abundant near the sea bed at night (J. Zeldis unpubl. data). These intra-specific vertical behavioural differences are to be expected in larvae, as they are most likely driven not only by local hydrodynamics, but also by site-specific prey availability and diel movements (Kinoshita \& Tanaka 1990, Murphy et al. 2011).

\section{ENSO effects on larval dispersal}

Within the southern Pacific, the ENSO cycle is a dominant source of year-to-year variability (Power et 
al. 2013) with clear links between ENSO states and fisheries productivity (Blanco et al. 2007, AburtoOropeza et al. 2010, Feltrim \& Ernst 2010). Increases in the abundance and survival of snapper larvae appear to be correlated with higher SST (Francis 1994, Sim-Smith et al. 2013), zooplankton abundances (Zeldis et al. 2005, Murphy et al. 2013) and onshore winds (Sim-Smith et al. 2013), conditions usually associated with La Niña years. Predictions from our biophysical model suggest that El Niño conditions may lead to a greater number of settlement-stage larvae transported within swimming range $(\leq 10 \mathrm{~km})$ of suitable settlement areas (Zones 2 and 3), compared to La Niña conditions. The benefits of transport to suitable settlement habitats may to some extent offset the decrease in larval survival expected in El Niño years. Thus, although our model predicts snapper larval subsidies and local recruitment are more likely to be successful under El Niño conditions, other key biological attributes (larval mortality, prey availability) will be required to bolster the reliability of using ENSO models to anticipate changes in dispersal and recruitment success due to climate change. We acknowledge that variability within the El Niño and La Niña categories was not investigated in this study, as only one typical example of each was used. Further modelling using time-series data encompassing varying degrees of La Niña/El Niño anomalies would be required to generalise these patterns.

\section{Larval contributions from MPAs}

Our biophysical modelling suggests 63 to $75 \%$ of larvae spawned inside the CROP marine reserve will end up in favourable settlement zones under an El Niño scenario. With 14 times more adult snapper inside the MPA than in surrounding, non-protected areas, this high level of larval export is likely to lead to a disproportionate or 'substantial' larval contribution to surrounding areas, mostly within a relatively small scale $(\leq 40 \mathrm{~km})$. Within this area, the details of predicted settlement depend on both larval behaviour and ENSO patterns. One of the benefits of modelling is that it can elucidate site-specific contributions to larval cross subsidy. The large eddies that form near Cape Rodney at the southern end of the CROP marine reserve play a significant role in determining the fate of particles released from the marine reserve. Eddies contain upflows and downflows, which transport the particles vertically and hence affect the degree to which the particles are subsequently moved by wind-driven surface currents.
Other direct studies have also found that eddies are important for larval retention and exchange (Sponaugle et al. 2005).

\section{CONCLUSIONS}

Very little is known about the potential for larval subsidies from temperate MPAs to surrounding fished areas. Our biophysical modelling suggests trends similar to those reported in tropical systems (Christie et al. 2010, Harrison et al. 2012), with significant levels of larval contribution from protected populations to surrounding fished areas within a relatively small scale $(\leq 40 \mathrm{~km})$. Our modelling also indicates that snapper larval behavioural attributes can have a significant impact on dispersal, but the effects are site-specific and can also interact with climatic conditions in a complex manner. These larval behavioural attributes have a significant impact on the biophysical model predictions, and need to be better understood to permit more realistic coupling of biological and physical models. Empirical approaches are also vital. Although direct measurement of larval subsidy is difficult, costly and time-consuming, it is essential to evaluate, and hopefully validate, biophysical models and their predictions. It also follows that it will be especially useful to have both empirical and biophysical modelling approaches applied to the same locations and under the same conditions to progress that evaluation process. Thus, multiple approaches providing explicit examples of larval subsidy, and developing the biophysical modelling to generalise those findings, will both be critical to providing new understanding that will shape our approaches to conservation and sustainable fisheries in a changing ocean.

Acknowledgements. This work was partly funded by a University of Auckland cross-faculty research fund (project 3620171). The authors thank Professor M. O'Sullivan for his assistance during the initial stages of development.

\section{LITERATURE CITED}

Aburto-Oropeza O, Paredes G, Mascareñas-Osorio I, Sala E (2010) Climatic influence on reef fish recruitment and fisheries. Mar Ecol Prog Ser 410:283-287

Alheit J, Niquen M (2004) Regime shifts in the Humboldt Current ecosystem. Prog Oceanogr 60:201-222

Beldade R, Holbrook SJ, Schmitt RJ, Planes S, Malone D, Bernardi G (2012) Larger female fish contribute disproportionately more to self-replenishment. Proc Biol Sci 279:2116-2121

Black K, Oldman J, Hume T (2005) Dynamics of a 3-dimen- 
sional, baroclinic, headland eddy. N Z J Mar Freshw Res 39:91-120

- Blanco JA, Narváez Barandica JC, Viloria EA (2007) ENSO and the rise and fall of a tilapia fishery in northern Colombia. Fish Res 88:100-108

Blower DC, Pandolfi JM, Bruce BD, Gomez-Cabrera MDC, Ovenden JR (2012) Population genetics of Australian white sharks reveals fine-scale spatial structure, transoceanic dispersal events and low effective population sizes. Mar Ecol Prog Ser 455:229-244

Carreras-Carbonell J, Macpherson E, Pascual M (2007) High self-recruitment levels in a Mediterranean littoral fish population revealed by microsatellite markers. Mar Biol 151:719-727

> Christie MR, Tissot BN, Albins MA, Beets JP and others (2010) Larval connectivity in an effective network of marine protected areas. PLoS ONE 5:e15715

> Clark DL, Leis JM, Hay AC, Trnski T (2005) Swimming ontogeny of larvae of four temperate marine fishes. Mar Ecol Prog Ser 292:287-300

Cowen RK, Paris CB, Srinivasan A (2006) Scaling of connectivity in marine populations. Science 311:522-527

> Cowen RK, Sponaugle S (2009) Larval dispersal and marine population connectivity. Annu Rev Mar Sci 1:443-466

> Crossland J (1977) Seasonal reproductive cycle of snapper Chrysophrys auratus (Forster) in the Hauraki Gulf. N Z J Mar Freshw Res 11:37-60

Croucher A (2008) Recruitment cross-subsidy of snapper from reserves to fished populations. Department of Engineering Science Report No. 671, University of Auckland

Croucher AE, O'Sullivan MJ (1998) Numerical methods for contaminant transport in rivers and estuaries. Comput Fluids 27:861-878

Croucher AE, Bogle MGV, O'Sullivan MJ (2005) Coastal receiving environment assessment (CREA) - Report I: modelling framework. Auckland UniServices, Auckland

D'Aloia CC, Bogdanowicz SM, Majoris JE, Harrison RG, Buston PM (2013) Self-recruitment in a Caribbean reef fish: a method for approximating dispersal kernels accounting for seascape. Mol Ecol 22:2563-2572

Egli D (2007) Population dynamics and individual movement of snapper, Pagrus auratus, in a temperate marine reserve. PhD thesis, University of Auckland

Egli DP, Babcock RC (2004) Ultrasonic tracking reveals multiple behavioural modes of snapper (Pagrus auratus) in a temperate no-take marine reserve. ICES J Mar Sci 61: 1137-1143

> Feltrim M, Ernst B (2010) Inter-cohort growth variability and its implication for fishery management of the common sardine (Strangomera bentincki) stock off the coast of south-central Chile. Fish Res 106:368-377

Foreman MGG (1977) Manual for tidal heights analysis and prediction (2004 revision). Pacific Marine Science Report 77-10, Institute of Ocean Sciences, Sidney

- Francis MP (1994) Duration of larval and spawning periods in Pagrus auratus (Sparidae) determined from otolith daily increments. Environ Biol Fishes 39:137-152

Francis MP, Pankhurst NW (1988) Juvenile sex inversion in the New Zealand snapper Chrysophrys auratus (Bloch \& Schneider, 1801) (Sparidae). Aust J Mar Freshw Res 39: 625-631

Gilbert DJ, McKenzie JR (1999) Sources of bias in biomass estimates from tagging programmes in the SNA 1 snapper (Pagrus auratus) stock. New Zealand Fisheries Assessment Research Document 99/16. NIWA, Wellington
Hamer PA, Jenkins GP, Acevedo S (2010) Importance of spawning in Port Phillip Bay to local snapper stocks. Fisheries Victoria Research Report Series No. 37, Department of Primary Industries, Melbourne

> Harrison HB, Williamson DH, Evans RD, Almany GR and others (2012) Larval export from marine reserves and the recruitment benefit for fish and fisheries. Curr Biol 22: 1023-1028

Jones GP, Planes S, Thorrold SR (2005) Coral reef fish larvae settle close to home. Curr Biol 15:1314-1318

Kaplan DM (2006) Alongshore advection and marine reserves: consequences for modeling and management. Mar Ecol Prog Ser 309:11-24

King IP (2008) A finite element model for stratified flow: RMA-10 user's guide, version 8.0B. Resource Modelling Associates, Sydney

> Kinoshita I, Tanaka M (1990) Differentiated spatial distribution of larvae and juveniles of two sparids, red and black sea bream, in Shijiki Bay. Bull Jpn Soc Sci Fish 56: 1807-1813

Kough AS, Paris CB, Butler MJIV (2013) Larval connectivity and the international management of fisheries. PLoS ONE 8:e64970

Lacroix G, Maes GE, Bolle LJ, Volckaert FAM (2013) Modelling dispersal dynamics of the early life stages of a marine flatfish (Solea solea L.). J Sea Res 84:13-25

> Leis JM (2006) Are larvae of demersal fishes plankton or nekton? Adv Mar Biol 51:57-141

Leis JM (2007) Behaviour as input for modelling dispersal of fish larvae: behaviour, biogeography, hydrodynamics, ontogeny, physiology and phylogeny meet hydrography. Mar Ecol Prog Ser 347:185-193

> Leis JM, Hay AC, Trnski T (2006) In situ ontogeny of behaviour in pelagic larvae of three temperate, marine, demersal fishes. Mar Biol 148:655-669

Leis JM, Hay AC, Lockett MM, Chen JP, Fang LS (2007a) Ontogeny of swimming speed in larvae of pelagicspawning, tropical, marine fishes. Mar Ecol Prog Ser 349: 255-267

> Leis JM, Wright KJ, Johnson RN (2007b) Behaviour that influences dispersal and connectivity in the small, young larvae of a reef fish. Mar Biol 153:103-117

Limouzy-Paris CB, Graber HC, Jones DL, Röpke AW, Richards WJ (1997) Translocation of larval coral reef fishes via sub-mesoscale spin-off eddies from the Florida Current. Bull Mar Sci 60:966-983

> Lo-Yat A, Simpson SD, Meekan M, Lecchini D, Martinez E, Galzin R (2011) Extreme climatic events reduce ocean productivity and larval supply in a tropical reef ecosystem. Glob Change Biol 17:1695-1702

> McPhaden MJ, Zebiak SE, Glantz MH (2006) ENSO as an integrating concept in Earth science. Science 314: 1740-1745

Ministry for Primary Industries (2013) Fisheries Assessment Plenary, May 2013: stock assessments and yield estimates. Compiled by the Fisheries Science Group, Ministry for Primary Industries, Wellington

Montgomery JC, Jeffs AG, Simpson SD, Meekan M, Chris T (2006) Sound as an orientation cue for the pelagic larvae of reef fishes and decapod crustaceans. Adv Mar Biol 51: 143-196

Mullan B (1996) Effects of ENSO on New Zealand and the South Pacific. In: Braddock D (ed) Prospects and needs for climate forecasting. Miscellaneous Series 34. Royal Society of New Zealand, Wellington 
Munday PL, Leis JM, Lough JM, Paris CB, Kingsford MJ, Berumen ML, Lambrechts J (2009) Climate change and coral reef connectivity. Coral Reefs 28:379-395

Murphy HM, Jenkins GP, Hamer PA, Swearer SE (2011) Diel vertical migration related to foraging success in snapper Chrysophrys auratus larvae. Mar Ecol Prog Ser 433:185-194

> Murphy HM, Jenkins GP, Hamer PA, Swearer SE (2013) Interannual variation in larval abundance and growth in snapper Chrysophrys auratus (Sparidae) is related to prey availability and temperature. Mar Ecol Prog Ser 487:151-162

> Palumbi SR (2004) Fisheries science: why mothers matter. Nature 430:621-622

> Pankhurst PM, Montgomery JC, Pankhurst NW (1991) Growth, development and behaviour of artificially reared larval Pagrus auratus (Bloch \& Schneider, 1801) (Sparidae). Mar Freshw Res 42:391-398

Paris CB, Cowen RK, Claro R, Lindeman KC (2005) Larval transport pathways from Cuban snapper (Lutjanidae) spawning aggregations based on biophysical modeling. Mar Ecol Prog Ser 296:93-106

> Parsons DM, Morrison MA, Slater MJ (2010) Responses to marine reserves: decreased dispersion of the sparid Pagrus auratus (snapper). Biol Conserv 143:2039-2048

Paulin CD (1990) Pagrus auratus, a new combination for the species known as 'snapper' in Australasian waters (Pisces: Sparidae). N Z J Mar Freshw Res 24:259-265

Pelc RA, Baskett ML, Tanci T, Gaines SD, Warner RR (2009) Quantifying larval export from South African marine reserves. Mar Ecol Prog Ser 394:65-78

Planes S, Jones GP, Thorrold SR (2009) Larval dispersal connects fish populations in a network of marine protected areas. Proc Natl Acad Sci USA 106:5693-5697

Power S, Delage F, Chung C, Kociuba G, Keay K (2013) Robust twenty-first-century projections of El Niño and related precipitation variability. Nature 502:541-545

Quillfeldt P, Masello JF (2013) Impacts of climate variation and potential effects of climate change on South American seabirds - a review. Mar Biol Res 9:337-357

Radford CA, Sim-Smith CJ, Jeffs AG (2012) Can larval snapper, Pagrus auratus, smell their new home? Mar Freshw Res 63:898-904

Ruegg K, Rosenbaum HC, Anderson EC, Engel M, Rothschild A, Baker CS, Palumbi SR (2013) Long-term population size of the North Atlantic humpback whale within the context of worldwide population structure. Conserv Genet 14:103-114

Russ GR, Alcala AC, Maypa AP, Calumpong HP, White AT (2004) Marine reserve benefits local fisheries. Ecol Appl 14:597-606

Saenz-Agudelo P, Jones GP, Thorrold SR, Planes S (2011) Connectivity dominates larval replenishment in a coastal reef fish metapopulation. Proc Biol Sci 278:2954-2961

Sale PF, Cowen RK, Danilowicz BS, Jones GP and others

Editorial responsibility: Stylianos Somarakis,

Heraklion, Greece
(2005) Critical science gaps impede use of no-take fishery reserves. Trends Ecol Evol 20:74-80

> Schiel DR (2011) Biogeographic patterns and long-term changes on New Zealand coastal reefs: non-trophic cascades from diffuse and local impacts. J Exp Mar Biol Ecol 400:33-51

> Scott SG, Zeldis JR, Pankhurst NW (1993) Evidence of daily spawning in natural populations of the New Zealand snapper Pagrus auratus (Sparidae). Environ Biol Fishes 36:149-156

Sim-Smith CJ, Jeffs AG, Radford CA (2013) Environmental influences on the larval recruitment dynamics of snapper, Chrysophrys auratus (Sparidae). Mar Freshw Res 64: 726-740

Smith ANH, Anderson MJ, MIllar RB, Willis TJ (2014) Effects of marine reserves in the context of spatial and temporal variation: an analysis using Bayesian zeroinflated mixed models. Mar Ecol Prog Ser 499:203-216

Sponaugle S, Lee T, Kourafalou V, Pinkard D (2005) Florida Current frontal eddies and the settlement of coral reef fishes. Limnol Oceanogr 50:1033-1048

> Tallmon DA, Waples RS, Gregovich D, Schwartz MK (2012) Detecting population recovery using gametic disequilibrium-based effective population size estimates. Conserv Genet Resour 4:987-989

Timmermann A, Oberhuber J, Bacher A, Esch M, Latif M, Roeckner E (1999) Increased El Niño frequency in a climate model forced by future greenhouse warming. Nature 398:694-697

Trnski T (2002) Behaviour of settlement-stage larvae of fishes with an estuarine juvenile phase: in situ observations in a warm-temperate estuary. Mar Ecol Prog Ser 242:205-214

Usmar NR (2009) Ontogeny and ecology of snapper (Pagrus auratus) in an estuary, the Mahurangi Harbour. PhD thesis, University of Auckland

- Walters RA, Goring DG, Bell RG (2001) Ocean tides around New Zealand. N Z J Mar Freshw Res 35:567-579

Willis TJ, Parsons DM, Babcock RC (2001) Evidence for long-term site fidelity of snapper (Pagrus auratus) within a marine reserve. N Z J Mar Freshw Res 35:581-590

Willis TJ, Millar RB, Babcock RC (2003) Protection of exploited fish in temperate regions: high density and biomass of snapper Pagrus auratus (Sparidae) in northern New Zealand marine reserves. J Appl Ecol 40:214-227

Yeh SW, Kug JS, Dewitte B, Kwon MH, Kirtman BP, Jin FF (2009) El Niño in a changing climate. Nature 461: 511-514

Zeldis JR, Francis R (1998) A daily egg production method estimate of snapper biomass in Hauraki Gulf, New Zealand. ICES J Mar Sci 55:522-534

Zeldis JR, Oldman J, Ballara SL, Richards LA (2005) Physical fluxes, pelagic ecosystem structure, and larval fish survival in Hauraki Gulf, New Zealand. Can J Fish Aquat Sci 62:593-610

Submitted: November 18, 2013; Accepted: July 25, 2014 Proofs received from author(s): October 29, 2014 